CLINICAL STUDY

\title{
Progressively increased patterns of subclinical cortisol hypersecretion in adrenal incidentalomas differently predict major metabolic and cardiovascular outcomes: a large cross-sectional study
}

Guido Di Dalmazi, Valentina Vicennati, Eleonora Rinaldi, Antonio Maria Morselli-Labate, Emanuela Giampalma ${ }^{1}$, Cristina Mosconi ${ }^{1}$, Uberto Pagotto and Renato Pasquali

Endocrinology Unit, Department of Clinical Medicine, S. Orsola-Malpighi Hospital, Alma Mater Studiorum, University of Bologna, Via Massarenti 9, 40138 Bologna, Italy and ${ }^{1}$ Division of Radiology, S. Orsola-Malpighi Hospital, 40138 Bologna, Italy

(Correspondence should be addressed to R Pasquali; Email: renato.pasquali@unibo.it)

\begin{abstract}
Background: Subclinical Cushing's syndrome (SCS) is defined as alterations in hypothalamic-pituitaryadrenal axis without classic signs/symptoms of glucocorticoid excess. Whether SCS leads to metabolic and cardiovascular diseases is still controversial.

Aim: To evaluate the prevalence of hypertension, type 2 diabetes (T2D), coronary heart disease (CHD), ischemic stroke, osteoporosis, and fractures, and their relationship to increasing patterns of subclinical hypercortisolism, in patients with nonsecreting adrenal adenomas (NSA) and SCS.

Methods: Using the $1 \mathrm{mg}$ dexamethasone suppression test (DST), 348 patients were classified as follows: 203 were defined as NSA and 19 SCS, using the most stringent cutoff values $(<50$ and $>138 \mathrm{nmol} / \mathrm{l}$ respectively). Patients with cortisol post-DST $(50-138 \mathrm{nmol} / \mathrm{l})$ were considered as intermediate phenotypes and classified as minor $(n=71)$ and major $(n=55)$ using plasma ACTH and/or urinary free cortisol as additional diagnostic tools.

Results: SCS patients showed higher prevalence of T2D, CHD, osteoporosis, and fractures with respect to NSA. Intermediate phenotypes also showed higher prevalence of CHD and T2D with respect to NSA. The prevalence of all clinical outcomes was not different between intermediate phenotype patients, which were therefore considered as a single group (IP) for multivariate logistic regression analysis: both IP and SCS-secreting patterns showed a significant association with CHD (odds ratio (OR), 4.09; 95\% confidence interval (CI), 1.47-11.38 and OR, 6.10; 95\% CI, 1.41-26.49 respectively), independently of other potential risk factors. SCS was also independently associated with osteoporosis (OR, 5.94; 95\% CI, 1.79-19.68).

Conclusions: Patterns of increasing subclinical hypercortisolism in adrenal adenomas are associated with increased prevalence of adverse metabolic and cardiovascular outcomes, independently of other potential risk factors.
\end{abstract}

European Journal of Endocrinology 166 669-677

\section{Introduction}

The clinical consequences of subclinical hypercortisolism in adrenal incidentalomas are still a matter of debate because even defining this condition is controversial due to lack of consensus on diagnostic criteria and the difficulty in defining a specific phenotype (1). Subclinical Cushing's syndrome (SCS) is defined as alterations of the hypothalamic-pituitary-adrenal (HPA) axis without classic signs or symptoms of glucocorticoid excess $(2,3)$. The widespread use of abdominal imaging techniques has increased the incidental finding of adrenal masses $(4,5)$ giving primary relevance to the diagnosis of SCS, which is found in up to $30 \%$ of adrenal incidentalomas $(6,7)$. Previous studies have highlighted the association between subclinical hypercortisolism and increased risk of osteoporosis, vertebral fractures (8), and cardiovascular diseases (CVDs) $(9,10)$ due to hypertension and metabolic alterations such as dyslipidemia and type 2 diabetes mellitus (T2D) (5). However, to date, no studies have investigated the relationship between adverse clinical outcomes, such as CVDs and stroke, and different degrees of subclinical cortisol hypersecretion.

The aim of the study was to evaluate the prevalence of hypertension, T2D, coronary heart disease (CHD), ischemic stroke, osteoporosis, and osteoporotic 
fractures, and the relationship of these outcomes to increasing patterns of subclinical cortisol hypersecretion, in patients with nonsecreting adrenal adenomas (NSA) and SCS.

\section{Materials and methods}

\section{Study population}

This study included 465 patients (282 females and 183 males, aged 18-87 years) referred to the Endocrinology Unit of the S. Orsola-Malpighi Hospital of Bologna, from 2000 to 2010, for an adrenal incidentaloma, as demonstrated by imaging studies (ultrasound, computed tomography (CT), magnetic resonance imaging (MRI)) performed for unrelated disorders. After referral, each patient underwent a CT scan, if not recently executed or if the adrenal mass was detected by ultrasound. All CT/MRI scans were reviewed by the same radiologists (E Giampalma and C Mosconi). Patients with the suspicion of adrenocortical carcinoma, metastases, myelolipoma, ganglioneuroma, cysts, pheochromocytoma, and infiltrative diseases were excluded, according to the radiological characteristics and/or diagnostic criteria described below. Patients with history of steroid intake within the last 3 months were not included in the study. Oral contraceptives and postmenopausal hormone replacement therapy were withdrawn for at least 3 months. Patients with clinical signs or symptoms specific to overt Cushing's syndrome (e.g. myopathy, plethora, purple striae, and easy bruising) were excluded. Patients with primary hyperaldosteronism were excluded on the basis of the more recent guidelines (11). Twenty-four hour urine for measurement of free metanephrines was carefully collected and conjugated with acid in all patients, who were instructed to abstain from catecholamine-containing products and acetaminophen for 8-10 days before collection. Patients with elevated urinary free metanephrines were also excluded (1).

Overall, 117 (25.2\%) subjects were excluded and 348 patients (217 females and 131 males, aged 28-87 years) were enrolled in the study.

\section{Investigational clinical protocol}

At study entry, history of cardiac risk factor, including hypertension, T2D, dyslipidemia, and smoking status, was acquired. History of nonfatal acute myocardial infarction, percutaneous transluminal coronary angioplasty/surgical bypass for ischemic heart disease, and ischemic/hemorrhagic stroke was also investigated. All cardiovascular events were reviewed and classified by an experienced cardiologist on the basis of hospital discharge letters. Clinical examination and electrocardiography were performed in all patients. Blood pressure was measured by mercury sphygmomanometer
(WBIC, Wenzhou, China) in each subject in clinostatic position, and 1 and $5 \mathrm{~min}$ after assumption of the standing position, according to the European Society of Hypertension guidelines (12). Arterial hypertension was diagnosed with systolic blood pressure $\geq 140 \mathrm{mmHg}$ and/or diastolic $\geq 90 \mathrm{mmHg}$, as measured on at least two separate occasions. Patients receiving antihypertensive medications were considered to have hypertension. Current smokers were defined as those currently smoking any type of tobacco, former smokers as those who had quit smoking at least 6 months before enrollment in the study, and nonsmokers as those who never smoked (13). First-degree family history of T2D, hypertension, CVDs, osteoporosis, and fractures was also investigated. All the patients underwent the same investigational protocol (see below).

\section{Anthropometry}

Height, body weight, waist and hip circumferences, and the waist-to-hip ratio were measured according to standardized procedures (14). Body mass index (BMI) was calculated as weight in kilograms per height in square meters.

\section{Hormonal and metabolic evaluation}

On the first day, blood samples for hormonal (cortisol and ACTH) and metabolic (glucose, lipids, and HbA1c) routine evaluation were drawn between 0800 and $0900 \mathrm{~h}$ after a $12 \mathrm{~h}$ overnight fast. Dyslipidemia was defined as total cholesterol levels $\geq 200 \mathrm{mg} / \mathrm{dl}$ and/or triglycerides $\geq 150 \mathrm{mg} / \mathrm{dl}$ (15). The day before, written instructions for $24 \mathrm{~h}$ urine collection for measurement of urinary free cortisol (UFC) (16) were given to each patient. Urinary outputs were normalized to urinary excretion of creatinine. Calcium balance (parathormone, calcium, phosphate, and 25-hydroxyvitamin $\mathrm{D}_{3}$ ) was also investigated on the first day to help in the diagnosis of osteopenia/osteoporosis (data not shown). An oral glucose tolerance test (75 g Curvosio; Sclavo, Cinisello Balsamo, Italy) was also performed in patients without known T2D by taking basal blood samples and after 30, 60, 90, and $120 \mathrm{~min}$ for glucose determination. The T2D was diagnosed according to the American Diabetes Association position statement (17). Patients who were taking antidiabetic drugs were considered as having T2D. On the same day, $1 \mathrm{mg}$ dexamethasone (Decadron; Visufarma, Rome, Italy) was administered at $2300 \mathrm{~h}$ and blood samples were taken the following morning (0800-0900 h), after a $12 \mathrm{~h}$ overnight fast, for cortisol measurement. Blood samples for hormone assays were immediately chilled on ice and centrifuged; serum, plasma, and urine aliquots were collected and frozen at $-20{ }^{\circ} \mathrm{C}$ and $-80{ }^{\circ} \mathrm{C}$ until assayed. All blood/urine samples were analyzed in the Central Laboratory of the S. OrsolaMalpighi Hospital of Bologna, Italy. 


\section{Grouping criteria of adrenal adenomas according to cortisol secretion}

According to National Institutes of Health (2) and American Association of Clinical Endocrinologists and American Association of Endocrine Surgeons (18) guidelines, SCS was diagnosed using the $1 \mathrm{mg}$ overnight dexamethasone suppression test (DST); different criteria were used to define normal cortisol suppression after DST and patterns of progressively increased subclinical cortisol hypersecretion. The most stringent cutoff values were preferred to reduce false positive results: cortisol post-DST $>138 \mathrm{nmol} / \mathrm{l}$ was used to define SCS, according to the high specificity of this cutoff in defining subclinical hypercortisolism, whereas cortisol post-DST $<50 \mathrm{nmol} / \mathrm{l}$ was used to define normal suppression. Notably, the cut-point of $50 \mathrm{nmol} / \mathrm{l}$ was used to define normal cortisol suppression and not SCS because although this cutoff value has been advocated to increase detection of SCS, it may lead to more false positive results $(19,20)$ due to its low specificity. Cortisol levels post-DST between 50 and $138 \mathrm{nmol} / \mathrm{l}$ were considered as intermediate cortisol suppression states; these patients were classified using at least another HPA axis alteration between high UFC and basal plasma ACTH $<10 \mathrm{pg} / \mathrm{ml}$. Although the use of UFC and/or ACTH in addition to the DST is an arbitrary choice, at least two alterations of the HPA axis for definition of subclinical hypercortisolism have been widely found and used in the previous literature $(21,22,23)$; moreover, it seems reasonable to consider low morning ACTH and/or high UFC as indices of autonomous cortisol hypersecretion, in addition to the partial cortisol suppression after DST. Finally, patients were classified as follows (shown in Table 1): patients with post-DST cortisol levels $<50 \mathrm{nmol} / \mathrm{l}$ were classified as having NSA, whereas those with cortisol post-DST $>138 \mathrm{nmol} / \mathrm{l}$ as having SCS; patients with cortisol post-DST between 50 and $138 \mathrm{nmol} / \mathrm{l}$ were divided into two groups: those with at least one alteration between high UFC and plasma ACTH

Table 1 Diagnostic criteria used to classify the different patterns of cortisol secretion.

\begin{tabular}{lrccc}
\hline & & \multicolumn{3}{c}{ Diagnostic criteria } \\
\cline { 2 - 5 } & $\boldsymbol{n}$ & $\begin{array}{c}\text { Cortisol }^{\mathrm{a}} \\
(\mathrm{nmol} / \mathrm{l})\end{array}$ & $\begin{array}{c}\text { Basal ACTH } \\
(\mathrm{pg} / \mathrm{ml})\end{array}$ & $\begin{array}{c}\text { UFC/24 } \mathrm{h} \\
(\mu \mathrm{g} / \mathrm{day})\end{array}$ \\
\hline Secreting pattern & & & & \\
NSA & 203 & $<50$ & - & - \\
ImP & 71 & $50-138$ & $\geq 10$ & $\leq 137$ \\
IMP & 55 & $50-138$ & $<10$ & $>137$ \\
SCS & 19 & $>138$ & - & - \\
\hline
\end{tabular}

${ }^{\mathrm{a} A f t e r} 1 \mathrm{mg}$ overnight DST.

bIntermediate phenotypes were defined with cortisol levels after DST between 50 and $138 \mathrm{nmol} / \mathrm{l}$ as primary criterion; IMP was defined with at least one alteration between UFC $>137 \mu \mathrm{g} /$ day and plasma ACTH $<10 \mathrm{pg} / \mathrm{ml}$; the remaining patients were defined as ImP.
$<10 \mathrm{pg} / \mathrm{ml}$ were defined as intermediate major phenotype (IMP), and those remaining as intermediate minor phenotype (ImP).

No further DSTs (e.g. 2-day low dose or $8 \mathrm{mg}$ ) were used as diagnostic tools because up to now there is still a lack of a head-to-head comparison of different DSTs to establish a gold standard for diagnosis of SCS (1) in nondiabetic patients (whereas in diabetics, the 2-day low-dose DST has been suggested to be the most specific test) (24). Moreover, similar cortisol suppression has been shown in both 1 and $8 \mathrm{mg}$ DSTs, thus the latter does not change the probability of SCS being defined by the former (25). Finally, as shown in a previous study (26), the standard $1 \mathrm{mg}$ dexamethasone dose did not differ in cortisol suppression from higher doses of dexamethasone (e.g. $0.015 \mathrm{mg} / \mathrm{kg}$ body weight), indicating the possibility of achieving the maximum suppressibility of the HPA axis with the $1 \mathrm{mg}$ DST.

\section{Bone metabolism evaluation}

Osteoporosis and osteoporotic fractures were recorded on the basis of clinical history, patient's medical records, and laboratory assessments (see above). Moreover, on the same days, Bone mass density (BMD) was measured by dual-energy X-ray absorptiometry (Lunar Corporation, Madison, WI, USA) in the antero-posterior view at femoral neck and lumbar spine. Osteoporosis and osteopenia were defined according to WHO criteria (27). T5-L5 morphometric X-ray absorptiometry was performed to assess vertebral fractures, which were diagnosed with a reduction $>25 \%$ in anterior, middle, or posterior vertebral height (28). Nonvertebral fractures due to minor trauma (falling from a standing position or while walking) and Colles fractures were also considered.

\section{Biochemical assays}

Serum cortisol was determined by electrochemiluminescence immunometric assay (ECLIA; Elecsys E170; Roche); intra-assay coefficient of variation (CV) was $<5 \%$. Cortisol was not measured by isotopic dilutionliquid chromatography-mass spectrometry; however, the comparison of this method with ECLIA assay revealed a good agreement for the latter in cortisol determination, as shown in our previous study (29). UFC was measured after extraction (liquid/liquid with dichloromethane) by ECLIA (Modular Elecsys E170; Roche); intra-assay CV was $<15 \%$. ACTH was determined by chemiluminescent immunoenzymatic assay (Immulite2000; Siemens Healthcare Diagnostics Inc, Tarrytown, NY, USA); intra-assay CV was $<10 \%$. Urinary metanephrines were measured by solid-phase extraction + HPLC with electrochemical detector. Glucose, lipids, and other hormones were measured as described previously (30). 


\section{Statistical analysis}

Statistical analysis was performed by SPSS version 12.0 statistical package (SPSS, Inc., Chicago, IL, USA). Comparison of general characteristics of the studied population among different groups was performed using one-way ANOVA (continuous variables) and the $\chi^{2}$ tests (categorical variables). Clinical outcomes were analyzed by means of the logistic regression analysis. The four groups were compared by means of the univariate analysis, and the simple contrasts were computed to assess pairwise differences between NSA, ImP, IMP, and SCS. Multivariate logistic regression analysis was used to evaluate the influence of different degrees of cortisol secretion rate (intermediate phenotype and SCS groups respectively) on the prevalence of clinical outcomes, using NSA as the reference group; this analysis was performed by adjusting for age, BMI, and gender for all variables; family history of diabetes was also added in the analysis of T2D, whereas smoking status, hypertension, T2D, and dyslipidemia were considered in the analysis of CHD; smoking status was also added in the analyses of osteoporosis and related fractures. The results are expressed as mean \pm s.D. or frequencies. Two-tailed $P$ values $<0.05$ were considered significant.

\section{Results}

According to the diagnostic criteria described above, among 348 patients, $203(58.3 \%)$ were defined as NSA (127 females and 76 males) and 19 (5.5\%) were diagnosed as SCS (11 females and eight males). Of the remaining 126 patients $(36.2 \%)$, 71 (20.4\%) were classified as ImP (35 females and 36 males) and $55(15.8 \%)$ as IMP (44 females and 11 males). Mean values of primary and secondary diagnostic tests in each group are shown in Table 2.

Anthropometric characteristics, smoking status, and medical treatments are reported in Table 3. BMI and waist circumference were comparable, whereas age $(P=0.001)$ and female-to-male ratio $(P=0.006)$ were significantly different among groups. The prevalence of menopause was similar in female patients. Use of diuretics and calcium-channel blockers was significantly increased in intermediate phenotypes and SCS with respect to NSA. No intergroup difference was detected in first-degree family history of T2D, hypertension, and CVDs (data not shown).

The prevalence of major clinical outcomes in NSA, ImP, IMP, and SCS patients is shown in Table 4. There was no significant difference in the prevalence of hypertension among groups. The prevalence of T2D was significantly higher in SCS (with respect to $\operatorname{ImP}$ and NSA) and in IMP patients (compared with NSA). The prevalence of CHD was significantly higher in ImP, IMP, and SCS groups with respect to NSA. IMP patients showed a higher prevalence of ischemic stroke compared with NSA patients. Only SCS patients showed a higher prevalence of osteoporosis (with respect to ImP, IMP, and NSA) and osteoporotic fractures (compared with NSA).

\section{Factors influencing the prevalence of T2D, CHD, osteoporosis, and fractures in inter- mediate phenotype and SCS patients}

Using the univariate logistic regression by applying simple contrast, no significant differences were shown in the prevalence of all clinical outcomes between ImP and IMP patients; therefore, they were considered as a single group (named IP) in the subsequent analyses. Table 5 shows the results of the multivariate logistic regression analyses evaluating the potential risk factors (including the cortisol-secreting pattern itself) for T2D, CHD, osteoporosis, and osteoporotic fractures, by comparing IP and SCS patients with the NSA group. The IP-secreting pattern was not associated with T2D, osteoporosis, and fractures but was significantly associated with CHD (odds ratio (OR), 4.09; 95\% confidence interval (CI), 1.47-11.38; $P=0.007$ )

Table 2 Values of the diagnostic criteria used to classify the different patterns of cortisol secretion. Criteria for diagnosis of NSA, ImP, IMP, and SCS are defined in Table 1.

\begin{tabular}{|c|c|c|c|c|c|}
\hline \multirow[b]{2}{*}{ Diagnostic criteria } & \multicolumn{4}{|c|}{ Secreting pattern } & \multirow[b]{2}{*}{$P$ value $^{a}$} \\
\hline & NSA & $\operatorname{ImP}$ & IMP & SCS & \\
\hline $1 \mathrm{mg} \mathrm{DST}$ & & & & & $<0.001$ \\
\hline Mean (S.D.) & $32.0(10.9)$ & $76.3^{\mathrm{b}}(23.6)$ & $84.3^{\mathrm{b}}(23.5)$ & $182.2^{\mathrm{b}, \mathrm{c}, \mathrm{d}}(37.3)$ & \\
\hline Median (min-max) & $33.1(5.5-49.7)$ & $66.2(52.4-132.4)$ & $80.0(52.4-137.9)$ & $176.6(146.2-267.6)$ & \\
\hline Basal ACTH & & & & & $<0.001$ \\
\hline Mean (S.D.) & $13.9(7.8)$ & $16.6^{\mathrm{e}}(7.7)$ & $6.6^{\mathrm{b}, \mathrm{c}}(2.2)$ & $10.6^{\mathrm{c}, \mathrm{d}, \mathrm{e}}(4.8)$ & \\
\hline Median (min-max) & $12.0(4.9-49.0)$ & $14.0(10.0-42.0)$ & $6.0(4.9-19.0)$ & $11.0(4.9-22.0)$ & \\
\hline 24-h UFC & & & & & 0.567 \\
\hline Mean (S.D.) & $56.3(26.9)$ & $55.0(23.7)$ & $62.1(40.8)$ & $59.9(34.1)$ & \\
\hline Median (min-max) & $44.0(36.0-137.0)$ & $48.0(36.0-133.0)$ & $42.5(36.0-179.0)$ & $45.0(36.0-148.0)$ & \\
\hline
\end{tabular}

aOne-way ANOVA.

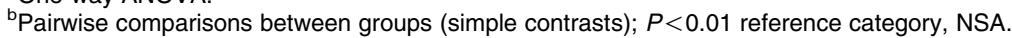

${ }^{\mathrm{C}}$ Pairwise comparisons between groups (simple contrasts); $P<0.01$ reference category, ImP.

${ }^{\mathrm{d}}$ Pairwise comparisons between groups (simple contrasts); $P<0.01$ reference category, IMP.

e Pairwise comparisons between groups (simple contrasts); $P<0.05$ reference category, NSA. 
Table 3 General characteristics of patients with different patterns of cortisol secretion. Data are given as mean \pm s.D. or as absolute numbers with percentage in parentheses. Criteria for diagnosis of NSA, ImP, IMP, and SCS are defined in Table 1.

\begin{tabular}{|c|c|c|c|c|c|}
\hline & \multicolumn{4}{|c|}{ Secreting pattern } & \multirow[b]{2}{*}{$P$ value } \\
\hline & NSA $(n=203)$ & $\operatorname{ImP}(n=71)$ & $\operatorname{IMP}(n=55)$ & $\operatorname{SCS}(n=19)$ & \\
\hline \multicolumn{6}{|l|}{ General characteristics } \\
\hline Females/males $(n ; \%)$ & $127 / 76(62 / 38)$ & $35 / 36(49 / 51)$ & $44 / 11(80 / 20)$ & $11 / 8(58 / 42)$ & $0.006^{\mathrm{a}}$ \\
\hline Age (years) & $60.3 \pm 10.9$ & $65.6 \pm 12.5$ & $61.3 \pm 9.9$ & $67.3 \pm 8.3$ & $0.001^{b}$ \\
\hline BMI $\left(\mathrm{kg} / \mathrm{m}^{2}\right)$ & $28.9 \pm 5.7$ & $28.6 \pm 6.3$ & $29.2 \pm 5.5$ & $28.4 \pm 3.7$ & $0.931^{b}$ \\
\hline Waist circumference $(\mathrm{cm})$ & $97.6 \pm 13.8$ & $98.0 \pm 15.2$ & $95.9 \pm 13.6$ & $98.3 \pm 12.3$ & $0.884^{\mathrm{b}}$ \\
\hline WHR & $0.92 \pm 0.09$ & $0.92 \pm 0.09$ & $0.91 \pm 0.09$ & $0.94 \pm 0.09$ & $0.748^{\mathrm{b}}$ \\
\hline Menopause $(n ; \%)$ & $114 / 127(89.8)$ & $31 / 35(88.6)$ & $40 / 44(90.9)$ & $11 / 11(100.0)$ & $0.714^{\mathrm{a}}$ \\
\hline Cigarette smoking status & & & & & $0.182^{\mathrm{a}}$ \\
\hline Never smoked $(n ; \%)$ & $110(54.2)$ & $35(49.3)$ & $24(43.6)$ & $11(57.9)$ & \\
\hline Former smoker $(n ; \%)$ & $42(20.7)$ & $12(16.9)$ & $8(14.5)$ & $1(5.3)$ & \\
\hline Current smoker $(n ; \%)$ & $51(25.1)$ & $24(33.8)$ & $23(41.8)$ & $7(36.8)$ & \\
\hline \multicolumn{6}{|l|}{ Therapy } \\
\hline Antihypertensive treatment $(n ; \%)$ & $108(53.2)$ & $46(64.8)$ & $36(65.4)$ & $16(84.2)$ & $0.021^{\mathrm{a}}$ \\
\hline Diuretics $(n ; \%)$ & $38(18.7)$ & $22(30.9)$ & $25(45.4)$ & $10(52.6)$ & $<0.001^{a}$ \\
\hline $\operatorname{ACEi}(n ; \%)$ & $49(24.1)$ & $26(36.6)$ & $19(34.5)$ & $7(36.8)$ & $0.126^{\mathrm{a}}$ \\
\hline ARBs $(n ; \%)$ & $21(10.3)$ & $9(12.6)$ & $10(18.2)$ & $3(15.8)$ & $0.441^{\mathrm{a}}$ \\
\hline$\beta$ Blockers $(n ; \%)$ & $43(21.2)$ & $15(21.1)$ & $10(18.2)$ & $8(42.1)$ & $0.166^{\mathrm{a}}$ \\
\hline CCBs $(n ; \%)$ & $28(13.8)$ & $18(25.3)$ & $11(20.0)$ & $7(36.8)$ & $0.022^{\mathrm{a}}$ \\
\hline$\alpha$ Blockers $(n ; \%)$ & $9(4.4)$ & $5(7.1)$ & $7(12.7)$ & $0(0.0)$ & $0.085^{\mathrm{a}}$ \\
\hline Antidiabetic treatment $(n ; \%)$ & $19(9.3)$ & $9(12.7)$ & $10(18.2)$ & $3(15.8)$ & $0.300^{\mathrm{a}}$ \\
\hline Metformin $(n ; \%)$ & $17(8.4)$ & $1(1.4)$ & $9(16.4)$ & $2(10.5)$ & $0.027^{\mathrm{a}}$ \\
\hline Sulfonylureas $(n ; \%)$ & $11(5.4)$ & $7(9.8)$ & $7(12.7)$ & $3(15.8)$ & $0.146^{\mathrm{a}}$ \\
\hline GLP1a/DPP-IVi $(n ; \%)$ & $1(0.5)$ & $0(0.0)$ & $0(0.0)$ & $0(0.0)$ & $0.869^{\mathrm{a}}$ \\
\hline Insulin $(n ; \%)$ & $2(0.9)$ & $3(4.2)$ & $0(0.0)$ & $1(5.3)$ & $0.130^{\mathrm{a}}$ \\
\hline Lipid-lowering treatment $(n ; \%)$ & $26(12.8)$ & $11(15.5)$ & $4(7.3)$ & $3(15.8)$ & $0.545^{\mathrm{a}}$ \\
\hline Statins $(n ; \%)$ & $21(10.3)$ & $7(9.8)$ & $4(7.3)$ & $3(15.8)$ & $0.757^{\mathrm{a}}$ \\
\hline Omega-3 $(n ; \%)$ & $5(2.4)$ & $4(5.6)$ & $1(1.8)$ & $0(0.0)$ & $0.417^{\mathrm{a}}$ \\
\hline Fibrates $(n ; \%)$ & $0(0.0)$ & $1(1.4)$ & $0(0.0)$ & $0(0.0)$ & $0.271^{\mathrm{a}}$ \\
\hline Osteoporosis treatment $(n ; \%)$ & $14(6.9)$ & $5(7.0)$ & $4(7.3)$ & $1(5.3)$ & $0.993^{\mathrm{a}}$ \\
\hline Calcium + vitamin D $(n ; \%)$ & $12(5.9)$ & $1(1.4)$ & $3(5.4)$ & $1(5.3)$ & $0.503^{\mathrm{a}}$ \\
\hline Bisphosphonates $(n ; \%)$ & $10(4.9)$ & $4(5.6)$ & $2(3.6)$ & $0(0.0)$ & $0.740^{\mathrm{a}}$ \\
\hline
\end{tabular}

WHR, waist-to-hip ratio; ACEi, ACE inhibitors; ARBs, angiotensin receptor blockers; CCBs, calcium-channel blockers; GLP1a, GLP1 agonists; DPP-IVi, DPP-IV inhibitors.

${ }^{a} \chi^{2}$ test.

'One-way ANOVA.

without the contribution of any other potential risk factor. The SCS-secreting pattern was also associated with CHD (OR, 6.10; 95\% CI, 1.41-26.49; $P=0.016)$ and osteoporosis (OR, 5.94; 95\% CI, 1.79-19.68; $P=0.004$ ), without any influence of the other potential risk factors; finally, this secreting pattern was significantly associated with T2D (OR, 3.44; 95\% CI, 1.1810.04; $P=0.024)$ and osteoporotic fractures (OR, 6.53; 95\% CI, 1.29-32.99; $P=0.023$ ) but with an independent significant contribution of age.

\section{Discussion}

This study shows that patients with incidentally discovered adrenal adenomas associated with progressively increased patterns of subclinical hypercortisolism have increasing prevalence of $\mathrm{T} 2 \mathrm{D}, \mathrm{CHD}$, osteoporosis, and osteoporotic fractures with respect to those with NSA. Our data also suggest that subclinical hypercortisolism per se is a risk factor for specific adverse outcomes, independently of other known risk factors.
It is well known that chronic overt hypercortisolism, as in Cushing's syndrome, is characterized by systemic alterations that may lead to increased risk of metabolic and CVDs (31). However, to date, there are no clear data supporting that subclinical hypercortisolism may lead to severe clinical consequences. This may be due to the lack of large cross-sectional and longitudinal studies and limitations concerning the diagnosis of SCS, which is still a matter of controversial procedures (32); indeed, there is consensus neither on the dosage of dexamethasone for the DST nor on the cutoff values for cortisol post-DST (33). According to our diagnostic criteria, we were able to identify one well-defined group without alterations in cortisol secretion (NSA) and three groups with increased patterns of autonomous cortisol hypersecretion (ImP, IMP, and SCS).

The significant association of SCS and T2D clearly confirms that even subclinical hypercortisolism has a profound impact on glucose metabolism, according to previous findings $(9,34)$. However, this association was not confirmed in IP patients, suggesting that alterations of glucose metabolism may be related to the degree of 
Table 4 Clinical outcomes in groups of patients with different patterns of cortisol secretion. Data are given as absolute numbers with percentage in parentheses. Criteria for diagnosis of NSA, ImP, IMP, and SCS are defined in Table 1.

\begin{tabular}{|c|c|c|c|c|c|}
\hline & \multicolumn{4}{|c|}{ Secreting pattern } & \multirow[b]{2}{*}{$\boldsymbol{P}$ value $^{\mathrm{a}}$} \\
\hline & NSA $(n=203)$ & $\operatorname{ImP}(n=71)$ & IMP $(n=55)$ & $\operatorname{SCS}(n=19)$ & \\
\hline \multicolumn{6}{|l|}{ Clinical outcomes } \\
\hline Hypertension $(n ; \%)$ & $149(73.4)$ & $58(81.7)$ & $43(78.2)$ & $18(94.7)$ & 0.173 \\
\hline $\mathrm{T} 2 \mathrm{D}(n ; \%)$ & $31(15.2)$ & $13(18.3)$ & $18(32.7)^{\mathrm{b}}$ & $8(42.1)^{b, c}$ & 0.004 \\
\hline $\mathrm{CHD}(n ; \%)$ & $6(2.9)$ & $9(12.6)^{b}$ & $6(10.9)^{d}$ & $5(26.3)^{\mathrm{b}}$ & 0.002 \\
\hline Stroke $(n ; \%)$ & $1(0.5)$ & $2(2.8)$ & $3(5.4)^{d}$ & $1(5.2)$ & 0.194 \\
\hline Osteoporosis ( $n$; \%) & $30(14.8)$ & $7(9.8)$ & $8(14.5)$ & $9(47.3)^{\mathrm{b}, \mathrm{e}, \mathrm{f}}$ & 0.003 \\
\hline $\begin{array}{l}\text { Osteoporotic } \\
\text { fractures }(n ; \%)\end{array}$ & $5(2.5)$ & $3(4.2)$ & $1(1.8)$ & $3(15.8)^{d}$ & 0.056 \\
\hline
\end{tabular}

${ }^{\mathrm{a}}$ Comparisons of outcomes among the four groups (univariate logistic regression).

${ }^{b}$ Pairwise comparisons between groups (simple contrasts applied to the logistic regression): $P<0.01$ reference category, NSA

${ }^{\mathrm{c} P a i r w i s e}$ comparisons between groups (simple contrasts applied to the logistic regression): $P<0.05$ reference category, ImP.

${ }^{\mathrm{d}}$ Pairwise comparisons between groups (simple contrasts applied to the logistic regression): $P<0.05$ reference category, NSA.

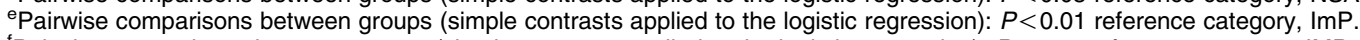

${ }^{f}$ Pairwise comparisons between groups (simple contrasts applied to the logistic regression): $P<0.01$ reference category, IMP.

cortisol hypersecretion, which may indeed play an independent negative role. In fact, as also demonstrated in patients with Cushing's syndrome (35), cortisol excess has been shown to: inhibit insulin secretion $(36,37)$, glucose uptake, and glycogen synthesis $(38,39)$; worsen insulin sensitivity; and increase gluconeogenesis.

The association between different patterns of subclinical hypercortisolism and CHD is novel and deserves more attention. We found that the prevalence of CHD progressively increased in ImP, IMP, and even more in the SCS group when compared with the NSA group. Interestingly, we have shown for the first time that the relationship between CHD and subclinical hypercortisolism was totally independent of other potential contributing factors. It is well known that overt cortisol excess, as in Cushing's syndrome, may lead to systemic complications responsible for increased cardiovascular risk (31) (hypertension, visceral obesity, impaired glucose metabolism, dyslipidemia, and thrombotic diathesis) and cardiovascular complications such as CHD, congestive heart failure, and cardiac stroke, leading to an elevated mortality rate $(40,41,42)$. Studies performed on patients with SCS are still unclear, although a prevalence of $17.9 \%$ has been reported in one study (43). Our data also suggest that subclinical hypercortisolism may represent per se an independent risk factor for $\mathrm{CHD}$ and that this risk tends to increase according to the cortisol-secreting pattern. Potential mechanisms involved in the pathogenesis of CHD in subclinical hypercortisolism may involve morphological and functional changes in vascular smooth muscle (44), endothelial cells (45), myocardium (46), and left ventricular dysfunction (47), although this should be adequately confirmed.

Finally, we found that the prevalence of osteoporosis (independently of other potential risk factors) and osteoporotic fractures (with an independent significant contribution of age) increased in patients with SCS. The worsening of BMD and the deleterious effects of cortisol on bone turnover are well described in patients with Cushing's syndrome (48) who have increased bone resorption rate, reduced osteoblastic activity, and increased osteoblast and osteocyte apoptosis $(49,50)$. Whether the same mechanisms are involved in patients with SCS is still unclear as previous studies reported worsening in BMD and spinal deformity index and increased risk of vertebral fractures $(51,52)$, while others did not confirm these findings (53). A recent longitudinal study reported an independent association between SCS and vertebral fractures, with an incidence of new fractures of $48 \%$ after 2 years of follow-up (54). Our data confirm that even moderate cortisol excess may worsen osteoporosis and increase osteoporotic fractures. However, caution must be exercised in interpreting the data because none of the SCS patients with fractures were on specific therapy at the time of diagnosis, which was first performed during the work-up of the adrenal mass.

Additional limits of the study are the lack of data about follow-up, due to its cross-sectional design, and the inability to define the length of exposure to the hypercortisolism. Finally, we have to acknowledge that some of the criteria used to stratify the groups were relatively arbitrary; however, we tried to use the available guidelines. Conversely, the strengths of the study are the homogeneity of the groups, given to the strict inclusion and exclusion criteria, and the strict clinical and biochemical criteria used in the diagnosis of different outcomes.

In conclusion, this is the first large cross-sectional study showing that adverse metabolic and cardiovascular outcomes are significantly associated with increasing patterns of subclinical hypercortisolism due to adrenal adenomas, independently of other potential risk factors for each specific outcome. Although these findings need to be confirmed by prospective studies, they raise questions about the need for more reliable and sensitive tests to diagnose subclinical hypercortisolism. On the other hand, our findings could indeed help in therapeutic decision making (conservative vs surgery approach), particularly in patients with adenomas associated with SCS. 


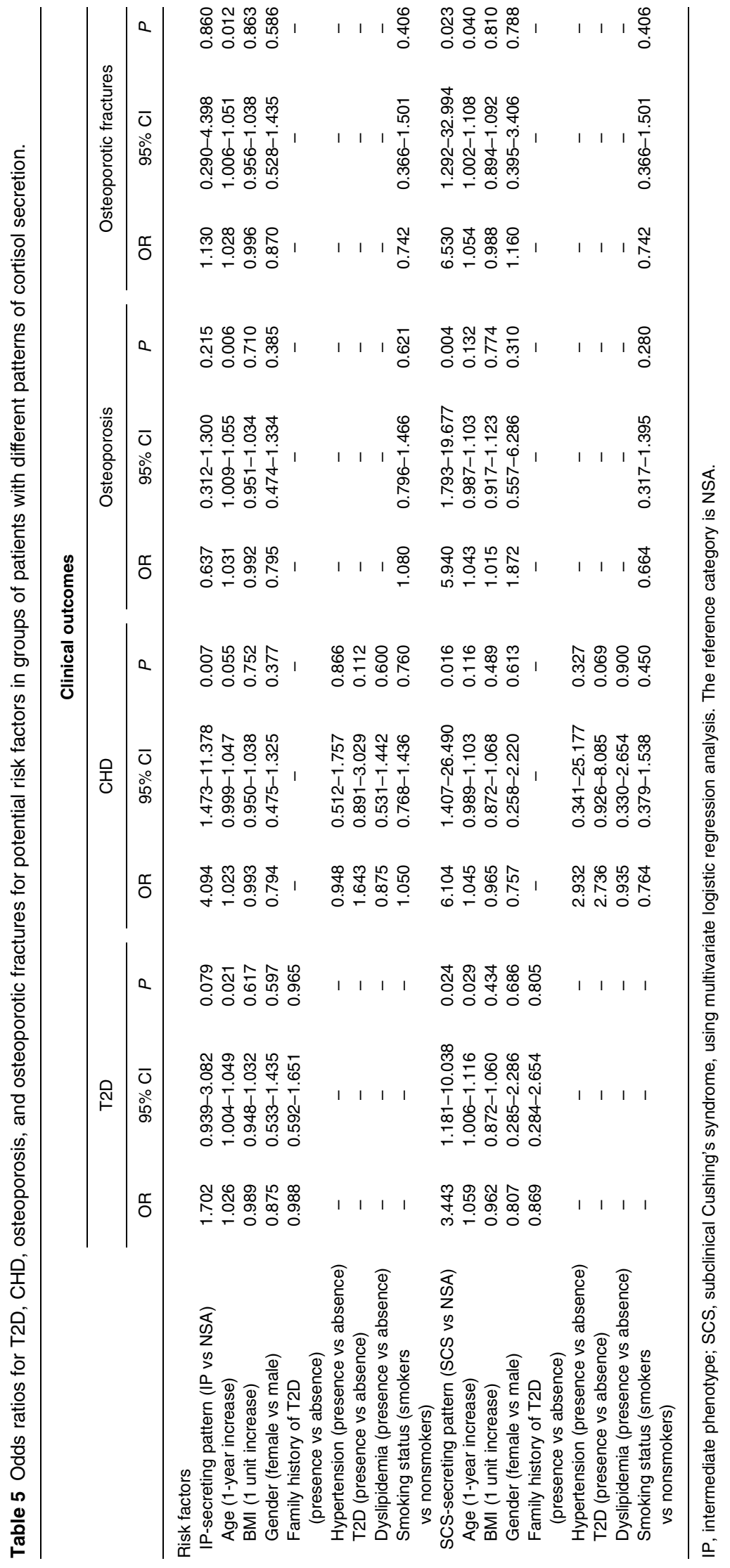




\section{Declaration of interest}

The study was conducted in accordance with the guiding principles of the Declaration of Helsinki, and all patients provided written informed consent for all the investigations performed according to usual clinical practice as well as for anonymous data publication. No IRB protocol approval was needed because the data were collected in the course of usual clinical practice. All authors have completed the ICMJE uniform disclosure form at www.icmje.org/coi_disclosure.pdf (available on request from the corresponding author) and declare no support from any organization for the submitted work, no financial relationships with any organizations that might have an interest in the submitted work in the previous 3 years, and no other relationships or activities that could appear to have influenced the submitted work.

\section{Funding}

This research did not receive any specific grant from any funding agency in the public, commercial or not-for-profit sector.

\section{Acknowledgement}

The authors thank Ms Susan West for the English revision of the manuscript.

\section{References}

1 Terzolo M, Stigliano A, Chiodini I, Loli P, Furlani L, Arnaldi G, Reimondo G, Pia A, Toscano V, Zini M, Borretta G, Papini E, Garofalo P, Allolio B, Dupas B, Mantero F, Tabarin A \& Italian Association of Clinical Endocrinologists. AME position statement on adrenal incidentaloma. European Journal of Endocrinology 2011 164 851-870. (doi:10.1530/EJE-10-1147)

$2 \mathrm{NIH}$ state-of-the-science statement on management of the clinically inapparent adrenal mass ("incidentaloma"). NIH Consensus and State-of-the-Science Statements 200219 1-25.

3 Reincke M. Subclinical Cushing's syndrome. Endocrinology and Metabolism Clinics of North America 200029 43-56. (doi:10. 1016/S0889-8529(05)70115-8)

4 Chidiac RM \& Aron DC. Incidentalomas. A disease of modern technology. Endocrinology and Metabolism Clinics of North America 199726 233-253. (doi:10.1016/S0889-8529(05)70242-5)

5 Kloos RT, Gross MD, Francis IR, Korobkin M \& Shapiro B. Incidentally discovered adrenal masses. Endocrine Reviews 1995 16 460-484. (doi:10.1210/edrv-16-4-460)

6 Mantero F, Terzolo M, Arnaldi G, Osella G, Masini AM, Alì A, Giovagnetti M, Opocher G \& Angeli A. A survey on adrenal incidentaloma in Italy. Study Group on Adrenal Tumors of the Italian Society of Endocrinology. Journal of Clinical Endocrinology and Metabolism 200085 637-644. (doi:10.1210/jc.85.2.637)

7 Terzolo M, Pia A, Alì A, Osella G, Reimondo G, Bovio S, Daffara F, Procopio M, Paccotti P, Borretta G \& Angeli A. Adrenal incidentaloma: a new cause of the metabolic syndrome? Journal of Clinical Endocrinology and Metabolism $2002 \mathbf{8 7}$ 998-1003. (doi:10.1210/jc.87.3.998)

8 Chiodini I, Guglielmi G, Battista C, Carnevale V, Torlontano M, Cammisa M, Trischitta V \& Scillitani A. Spinal volumetric bone mineral density and vertebral fractures in female patients with adrenal incidentalomas: the effects of subclinical hypercortisolism and gonadal status. Journal of Clinical Endocrinology and Metabolism 200489 2237-2241. (doi:10.1210/jc.2003031413)

9 Rossi R, Tauchmanova L, Luciano A, Di Martino M, Battista C, Del Viscovo L, Nuzzo V \& Lombardi G. Subclinical Cushing's syndrome in patients with adrenal incidentaloma: clinical and biochemical features. Journal of Clinical Endocrinology and Metabolism 200085 1440-1448. (doi:10.1210/jc.85.4.1440)
10 Erbil Y, Ademoğlu E, Ozbey N, Barbaros U, Yanik BT, Salmaslioğlu A, Bozbora A \& Ozarmağan S. Evaluation of the cardiovascular risk in patients with subclinical Cushing syndrome before and after surgery. World Journal of Surgery 200630 1665-1671. (doi:10.1007/s00268-005-0681-x)

11 Funder JW, Carey RM, Fardella C, Gomez-Sanchez CE, Mantero F, Stowasser M, Young WF Jr, Montori VM \& Endocrine Society. Case detection, diagnosis, and treatment of patients with primary aldosteronism: an Endocrine Society Clinical Practice Guideline. Journal of Clinical Endocrinology and Metabolism 200893 3266-3281. (doi:10.1210/jc.2008-0104)

12 European Society of Hypertension-European Society of Cardiology guidelines for the management of arterial hypertension. Journal of Hypertension 200321 1011-1053. (doi:10.1097/00004872200306000-00001)

13 Velicer WF \& Prochaska JO. A comparison of four self-report smoking cessation outcome measures. Addictive Behaviors 2004 29 51-60. (doi:10.1016/S0306-4603(03)00084-4)

14 World Health Organization. Measuring obesity-classification and description of anthropometric data. Copenhagen: World Health Org, 1988 (Eur/ICP/NUT 125-0612v).

15 Third Report of the National Cholesterol Education Program (NCEP) Expert Panel on Detection, Evaluation, and Treatment of High Blood Cholesterol in Adults (Adult Treatment Panel III) Final Report. Circulation 2002106 3143-3421.

16 Vicennati V, Pasqui F, Cavazza C, Pagotto U \& Pasquali R. Stress related development of obesity and cortisol in women. Obesity 200917 1678-1683. (doi:10.1038/oby.2009.76)

17 American Diabetes Association. Diagnosis and classification of diabetes mellitus. Diabetes Care 201033 S62-S69. (doi:10.2337/ dc10-S062)

18 Zeiger MA, Thompson GB, Duh QY, Hamrahian AH, Angelos P, Elaraj D, Fishman E \& Kharlip J. American Association of Clinical Endocrinologists and American Association of Endocrine Surgeons medical guidelines for the management of adrenal incidentalomas. Endocrine Practice 200915 1-20.

19 Valli N, Catargi B, Ronci N, Vergnot V, Leccia F, Ferriere JM, Chene G, Grenier N, Laurent F \& Tabarin A. Biochemical screening for subclinical cortisol-secreting adenomas amongst adrenal incidentalomas. European Journal of Endocrinology $2001 \mathbf{1 4 4}$ 401-408. (doi:10.1530/eje.0.1440401)

20 Barzon L, Fallo F, Sonino N \& Boscaro M. Development of overt Cushing's syndrome in patients with adrenal incidentaloma. European Journal of Endocrinology 2002146 61-66. (doi:10.1530/ eje.0.1460061)

21 Terzolo M, Osella G, Alì A, Borretta G, Cesario F, Paccotti P \& Angeli A. Subclinical Cushing's syndrome in adrenal incidentaloma. Clinical Endocrinology 199848 89-97. (doi:10.1046/j. 1365-2265.1998.00357.x)

22 Libè R, Dall'Asta C, Barbetta R, Baccarelli A, Beck-Peccoz P \& Ambrosi B. Long-term follow-up study of patients with adrenal incidentalomas. European Journal of Endocrinology 2002 147 489-494. (doi:10.1530/eje.0.1470489)

23 Masserini B, Morelli V, Bergamaschi S, Ermetici F, Eller-Vainicher C, Barbieri AM, Maffini MA, Scillitani A, Ambrosi B, Beck-Peccoz P \& Chiodini I. The limited role of salivary cortisol levels in the diagnosis of subclinical hypercortisolism in patients with adrenal incidentaloma. European Journal of Endocrinology 2009160 87-92. (doi:10.1530/EJE-08-0485)

24 Nieman LK, Biller BMK, Findling JW, Newell-Price J, Savage MO, Stewart PM \& Montori V. The diagnosis of Cushing's syndrome: an Endocrine Society Clinical Practice Guideline. Journal of Clinical Endocrinology and Metabolism 200893 1526-1540. (doi:10. 1210/jc.2008-0125)

25 Reimondo G, Allasino B. Bovio S, Saba L, Ardito A. Angeli A \& Terzolo M. Pros and cons of dexamethasone suppression test for screening of subclinical Cushing's syndrome in patients with adrenal incidentalomas. Journal of Endocrinological Investigation $2011341-5$.

26 Pasquali R, Ambrosi B, Armanini D, Cavagnini F, Uberti ED, del Rio G, de Pergola G, Maccario M, Mantero F, Marugo M, 
Rotella CM, Vettor R \& Study Group on Obesity of the Italian Society of Endocrinology. Cortisol and ACTH response to oral dexamethasone in obesity and effects of sex, body fat distribution, and dexamethasone concentrations: a dose-response study. Journal of Clinical Endocrinology and Metabolism $2002 \mathbf{8 7}$ 166-175. (doi:10.1210/jc.87.1.166)

27 WHO Study Group. Assessment of fracture risk and its application to screening for postmenopausal osteoporosis. Report of a WHO Study Group. World Health Organization Technical Report Series $19948431-129$.

28 Genant HK, Wu CY, van Kuijk C \& Nevitt MC. Vertebral fracture assessment using a semiquantitative technique. Journal of Bone and Mineral Research 19938 1137-1148. (doi:10.1002/jbmr. 5650080915)

29 Fanelli F, Belluomo I, Di Lallo VD, Cuomo G, De Iasio R, Baccini M, Casadio E, Casetta B, Vicennati V, Gambineri A, Grossi G, Pasquali R \& Pagotto U. Serum steroid profiling by isotopic dilution-liquid chromatography-mass spectrometry: comparison with current immunoassays and reference intervals in healthy adults. Steroids 201176 244-253. (doi:10.1016/j.steroids.2010.11.005)

30 Vicennati V, Ceroni L, Genghini S, Patton L, Pagotto U \& Pasquali R. Sex difference in the relationship between the hypothalamic-pituitary-adrenal axis and sex hormones in obesity. Obesity 200614 235-243. (doi:10.1038/oby.2006.30)

31 De Leo M, Pivonello R, Auriemma RS, Cozzolino A, Vitale P, Simeoli C, De Martino MC, Lombardi G \& Colao A. Cardiovascular disease in Cushing's syndrome: heart versus vasculature. Neuroendocrinology 2010 92 50-54. (doi:10.1159/000318566)

32 Mazzuco TL, Bordeau I \& Lacroix A. Adrenal incidentalomas and subclinical Cushing's syndrome: diagnosis and treatment. Current Opinion in Endocrinology, Diabetes, and Obesity 200916 203-210. (doi:10.1097/MED.0b013e32832b7043)

33 Morelli V, Masserini B, Salcuni AS, Eller-Vainicher C, Savoca C, Viti R, Coletti F, Guglielmi G, Battista C, Iorio L, Beck-Peccoz P, Ambrosi B, Arosio M, Scillitani A \& Chiodini I. Subclinical hypercortisolism: correlation between biochemical diagnostic criteria and clinical aspects. Clinical Endocrinology $2010 \mathbf{7 3}$ 161-166. (doi:10.1111/j.1365-2265.2010.03794.x)

34 Peppa M, Koliaki C \& Raptis SA. Adrenal incidentalomas and cardiometabolic morbidity: an emerging association with serious clinical implications. Journal of Internal Medicine 2010 268 555-566. (doi:10.1111/j.1365-2796.2010.02291.x)

35 Pivonello R, De Leo M, Vitale P, Cozzolino A, Simeoli C, De Martino MC, Lombardi G \& Colao A. Pathophysiology of diabetes mellitus in Cushing's syndrome. Neuroendocrinology 2010 92 77-81. (doi:10.1159/000314319)

36 Lambillotte C, Gilon P \& Henquin JC. Direct glucocorticoid inhibition of insulin secretion. An in vitro study of dexamethasone effects in mouse islets. Journal of Clinical Investigation 199799 414-423. (doi:10.1172/JCI119175)

37 Plat L, Byrne MM, Sturis J, Polonsky KS, Mockel J, Féry F \& Van Cauter E. Effects of morning cortisol elevation on insulin secretion and glucose regulation in humans. American Journal of Physiology 1996270 E36-E42.

38 Vegiopoulos A \& Herzig S. Glucocorticoids, metabolism and metabolic diseases. Molecular and Cellular Endocrinology 2007 275 43-61. (doi:10.1016/j.mce.2007.05.015)

39 van Raalte DH, Ouwens DM \& Diamant M. Novel insights into glucocorticoid-mediated diabetogenic effects: towards expansion of therapeutic options? European Journal of Clinical Investigation 2009 39 81-93. (doi:10.1111/j.1365-2362.2008.02067.x)

40 Etxabe J \& Vazquez JA. Morbidity and mortality in Cushing's disease: an epidemiological approach. Clinical Endocrinology 1994 40 479-484. (doi:10.1111/j.1365-2265.1994.tb02486.x)

41 Clayton RN, Raskauskiene D, Reulen RC \& Jones PW. Mortality and morbidity in Cushing's disease over 50 years in Stokeon-Trent, UK: audit and meta-analysis of literature. Journal of Clinical Endocrinology and Metabolism 2011 96 632-642. (doi:10. 1210/jc.2010-1942)

42 Lindholm J, Juul S, Jorgensen JO, Astrup J, Bjerre F, Feldt-Rasmussen U, Hagen C, Jørgensen J, Kosteljanetz M,
Kristensen L, Laurberg P, Schmidt K \& Weeke J. Incidence and late prognosis of Cushing's syndrome: a population-based study. Journal of Clinical Endocrinology and Metabolism 200186 117-123. (doi:10.1210/jc.86.1.117)

43 Tauchmanovà L, Rossi R, Biondi B, Pulcrano M, Nuzzo V, Palmieri EA, Fazio S \& Lombardi G. Patients with subclinical Cushing's syndrome due to adrenal adenoma have increased cardiovascular risk. Journal of Clinical Endocrinology and Metabolism 200287 4872-4878. (doi:10.1210/jc.2001-011766)

44 Baykan M, Erem C, Gedikli O, Hacihasanoglu A, Erdogan T, Kocak M, Durmuș I, Korkmaz L \& Celik S. Impairment of flowmediated vasodilatation of brachial artery in patients with Cushing's syndrome. Endocrine 200725 182-190.

45 Faggiano A, Pivonello R, Spiezia S, De Martino MC, Filippella M, Di Somma C, Lombardi G \& Colao A. Cardiovascular risk factors and common carotid artery calibre and stiffness in patients with Cushing's disease during active disease and 1 year after disease remission. Journal of Clinical Endocrinology and Metabolism 2003 88 2527-2533. (doi:10.1210/jc.2002-021558)

46 Walker BR. Glucocorticoids and cardiovascular disease. European Journal of Endocrinology 2007157 545-559. (doi:10.1530/EJE07-0455)

47 Muiesan ML, Lupia M, Slavetti M, Grigoletto C, Sonino M, Boscaro M, Rosei EA, Mantero F \& Fallo F. Left ventricular structural and functional characteristics in Cushing's syndrome. Journal of the American College of Cardiology $2003412275-2279$. (doi:10.1016/S0735-1097(03)00493-5)

48 Minetto M, Reimondo G, Osella G, Ventura M, Angeli A \& Terzolo M. Bone loss is more severe in primary than in pituitarydependent Cushing's syndrome. Osteoporosis International 2004 15 855-861. (doi:10.1007/s00198-004-1616-3)

49 Pienotti S, Gandini L, Lenzi A \& Isidori AM. Pre-receptorial regulation of steroid hormones in bone cells: insight on glucocorticoid-induced osteoporosis. Journal of Steroid Biochemistry and Molecular Biology 2008108 292-299. (doi:10.1016/j.jsbmb. 2007.09.018)

50 Mancini T, Doga M, Mazziotti G \& Giustina A. Cushing's syndrome and bone. Pituitary 20047 249-252. (doi:10.1007/s11102-0051051-2)

51 Chiodini I, Morelli V, Masserini B, Salcuni AS, Eller-Vainicher C, Viti R, Coletti F, Guglielmi G, Battista C, Carnevale V, Iorio L, Beck-Peccoz P, Arosio M, Ambrosi B \& Scillitani A. Bone mineral density, prevalence of vertebral fractures, and bone quality in patients with adrenal incidentalomas with and without subclinical hypercortisolism: an Italian multicenter study. Journal of Clinical Endocrinology and Metabolism 200994 3207-3214. (doi:10.1210/jc.2009-0468)

52 Chiodini I, Viti R, Coletti F, Guglielmi G, Battista C, Ermetici F, Morelli V, Salcuni A, Carnevale V, Urbano F, Muscarella S, Ambrosi B, Arosio M, Beck-Peccoz P \& Scillitani A. Eugonadal male patients with adrenal incidentalomas and subclinical hypercortisolism have increased rate of vertebral fractures. Clinical Endocrinology $2009 \mathbf{7 0}$ 208-213. (doi:10.1111/j.1365-2265. 2008.03310.x)

53 Osella G, Reimondo G, Peretti P, Alì A, Paccotti P, Angeli A \& Terzolo M. The patients with incidentally discovered adrenal adenoma (incidentaloma) are not at increased risk of osteoporosis. Journal of Clinical Endocrinology and Metabolism 200186 604-607. (doi:10.1210/jc.86.2.604)

54 Morelli V, Eller-Vainicher C, Salcuni AS, Coletti F, Iorio L, Muscogiuri G, Della Casa S, Arosio M, Ambrosi B, Beck-Peccoz P \& Chiodini I. Risk of new vertebral fractures in patients with adrenal incidentaloma with and without subclinical hypercortisolism: a multicenter longitudinal study. Journal of Bone and Mineral Research 201126 1816-1821. (doi:10.1002/jbmr.398)

Received 30 November 2011

Revised version received 13 January 2012

Accepted 20 January 2012 